\title{
OS DIREITOS DA NATUREZA
}

\section{Ronie Alexsandro Teles da Silveira ${ }^{1}$}

\section{Resumo}

O artigo parte da percepção de que existe um sentimento crescente, na cultura contemporânea, que demanda respeito pelos seres não humanos. Por sua vez, esse sentimento solicita o reconhecimento dos direitos da natureza. A partir dessa constatação, distinguem-se duas posições básicas que tentam tornar efetiva essa demanda: o direito instrumental e o direito próprio. $\mathrm{O}$ primeiro mantém um raciocínio instrumental que é típico da técnica. $\mathrm{O}$ segundo não pode ser conciliado com tal tipo de raciocínio. Para ganho de clareza, se compara rapidamente a noção medieval de natureza com aquela que forneceu a base para a ciência moderna e que se aliou historicamente com crenças monoteístas, especialmente as cristãs. Finaliza-se com a constatação de que a obtenção de uma validade cultural efetiva para o direito próprio da natureza, se ocorrer, implicará em duas frentes de disputa nada desprezíveis. Uma contra as crenças monoteístas e outra contra a base da cultura científica ocidental.

Palavras-chave: Natureza; Direito; Ciência; Técnica; Monoteísmo

\section{INTRODUÇÃO}

Todos nós sentimos, de uma maneira ou de outra, uma demanda atual e crescente para reconhecer a posse de direitos por parte dos seres não humanos. A presença dessa necessidade pode ser percebida de várias formas: nas discussões - cada vez mais frequentes - sobre a fundamentação ética desses direitos, na incontornável presença de preocupações ambientais, na prática efetiva de um tratamento mais cuidadoso com relação a animais etc.

\footnotetext{
${ }^{1}$ Doutorado em Psicologia pela Pontifícia Universidade Católica do Rio Grande do Sul. É professor associado da Universidade Federal do Sul da Bahia. E-mail: roniefilosofia@gmail.com
} 
Fornecendo sustentação a essas e outras atitudes semelhantes há um sentimento generalizado de que práticas utilizadas no passado com relação ao mundo não humano ou natural não são mais aceitáveis, hoje e no futuro. Esse sentimento encontra-se diluído no conjunto de valores do ambiente contemporâneo e embora ele possa ser exemplificado de várias formas, não pode ser adequadamente identificado com um ou outro evento em particular. Trata-se de um processo em curso que envolve uma alteração de nossa sensibilidade com relação à natureza.

Ainda assim, há uma maneira muito simples pela qual cada um de nós pode perceber a presença dessa mutação sentimental em nossas vidas: verifique se aqueles comportamentos corriqueiros da infância com relação ao mundo natural ainda parecem razoáveis e aceitáveis atualmente. Claro que essa comparação é mais fácil de ser realizada por pessoas da minha idade, para as quais já transcorreu um intervalo de tempo considerável desde a infância até o presente. Mas creio que isso se aplica mesmo aos mais jovens. Também eles poderão notar que algumas de suas atitudes habituais da época da infância com relação a animais e plantas são, hoje, consideradas gestos de crueldade cristalina.

Nossa sensibilidade tem se alterado de maneira inequívoca na direção de reconhecer que a natureza possui um valor específico e próprio. E é esse valor emergente que solicita, cada vez mais, uma atitude de respeito da parte dos humanos. Observe que essa mutação de nossa sensibilidade não exige um raciocínio explicito como sua causa. Ela diz respeito a tornar moralmente inadmissíveis aqueles antigos comportamentos que eram praticados, sem que se estabeleça necessariamente uma tomada de consciência explícita para isso. Essa mutação sentimental simplesmente está transformando velhas atitudes cotidianas em gestos absurdos de crueldade e desrespeito com relação aos seres não humanos. Ela tem sido tão intensa que esse novo comportamento respeitoso passou a ser considerado como parte essencial do comportamento humano. Do mesmo modo, ela tem provocado o efeito de que aquelas velhas atitudes passam a ser encaradas como típicas de pessoas destituídas de sentimentos humanos. De certa forma, essa mudança nos nossos sentimentos com relação à natureza envolveu alterar o próprio sentido daquilo que se entende por ser humano.

\section{DIREITO PRÓPRIO E DIREITO INSTRUMENTAL}

Gostaria de diferenciar essa mutação recente em nossa sensibilidade com relação aos seres não humanos de um raciocínio instrumental. Nesse último caso, o valor atribuído à natureza é derivado de uma ponderação em que os seres naturais valem algo somente enquanto promovem algum beneficio, direto ou indireto, aos seres humanos. Assim, quando afirmamos, por exemplo, que devemos preservar a natureza porque não podemos infringir o direito das futuras gerações a uma vida boa, não estamos compartilhando daquele sentimento que 
reconhece que o mundo natural é dotado de um valor próprio. Estamos indicando que o valor da natureza está na dependência de sua utilidade para os seres humanos do futuro.

Observe que o que se assevera aqui, no caso dessa última afirmação, é o direito das gerações futuras. Somente de maneira secundária e utilitária o direito da natureza é referido. Nesse caso, lançamos mão de um raciocínio instrumental em que o direito da natureza é uma decorrência da necessidade de preservar o bem-estar da humanidade. Esse tipo de raciocínio instrumental baseia-se em um cálculo em que a natureza desempenha a função de meio para uma finalidade humana. O valor da natureza, que é afirmado aqui, é aquele que é derivado das necessidades da própria espécie humana.

No raciocínio instrumental se alega que devemos preservar a natureza porque a lógica intrínseca dos atuais padrões de desenvolvimento econômico levaria a colocar em risco a nossa espécie. Jonas (1995) ressaltou a diferença de escala temporal e espacial entre esse raciocínio instrumental global e os cálculos contextuais da ética clássica. Em ambos os casos, no local e no global, o raciocínio é instrumental. Através dele, não se afirma que devemos preservar a natureza porque ela vale algo por si mesma, porque ela possui uma dimensão intrínseca que exige respeito pela sua própria constituição. Ou seja, trata-se de uma preocupação inicial com a nossa autopreservação enquanto espécie e não com o reconhecimento de um direito da natureza como tal. Através desse raciocínio instrumental se projeta efetivamente um direito sobre a natureza. Porém essa projeção é operada sobre uma natureza compreendida como meio de uma relação instrumental em que a humanidade é a finalidade e o parâmetro definitivo de avaliação e, portanto, de constituição do direito envolvido. A questão básica que obriga ao reconhecimento do direito da natureza é que sem ela a vida humana corre perigo de extinção. Ou seja, o núcleo do raciocínio instrumental é sempre a própria espécie humana e as consequências danosas que podem afetá-la.

Outra versão dessa mesma postura instrumental com relação aos direitos dos seres naturais envolve a percepção de que o problema com os atuais padrões de domínio técnico sobre a natureza é que eles são muito estreitos. Isso quer dizer que os problemas ambientais provocados pela civilização técnica seriam uma decorrência de certa incapacidade para se realizarem cálculos suficientes. Os danos ambientais causados pelo uso da técnica poderiam ser minimizados ou eliminados se nos tornássemos capazes de verificar antecipadamente todos os impactos possíveis produzidos por nossas intervenções sobre a natureza. Hoje não seríamos capazes de fazer isso, porque ignoramos a verdadeira complexidade do mundo natural, em função de adotarmos uma modalidade de conhecimento linear e simplificada.

Postula-se, então, que um pensamento complexo, uma forma de pensar mais sofisticada que levasse em consideração um número de variáveis muito superior que o atual, poderia nos capacitar para diminuir os impactos ambientais decorrentes do emprego da técnica. O que o pensamento complexo (MORIN, 2006) ou a teoria dos sistemas (BERTALANFFY, 1976) quer dizer, com relação a problemas ambientais, é que devemos ampliar nossa 
capacidade de cálculo de consequências indesejáveis decorrentes do uso da técnica. Essa perspectiva afirma, indiretamente, que não há nada de substancialmente errado com a maneira técnica de nos relacionarmos com a natureza. Para ela, o que estaria errado seria nossa incapacidade de pensar de maneira radicalmente técnica e calcular tudo o que estaria efetivamente envolvido em uma intervenção humana no mundo. Adotada essa forma de racionalidade complexa - e, portanto, de técnica superior - os problemas ambientais estariam resolvidos ou seriam minimizados, porque os efeitos indesejados poderiam ser evitados em função da melhoria do cálculo das consequências.

Observe que, também nesse caso, não se altera a posição secundária e instrumental desempenhada pela natureza. Uma técnica mais sofisticada, que é capaz de computar os menores efeitos naturais de nossas intervenções no mundo não humano, ainda é uma técnica - embora de um tipo muito superior. $\mathrm{O}$ direito da natureza que se agrega a essa forma de pensar deve parecer mais sofisticado por levar em consideração uma suposta complexidade natural. Porém, nele ainda se reserva o mesmo valor secundário para os seres não humanos - representados como meios. A humanidade constitui toda a finalidade de um raciocínio instrumental, seja ele simplificado ou complexo.

Quero ressaltar que o raciocínio instrumental, simples ou complexo, é totalmente diferente do conteúdo daquela mutação de nossa sensibilidade com relação à natureza a que me referi no início. Para facilitar o entendimento dessa diferença, sempre que me referir ao conteúdo dessa mutação de nossa sensibilidade, utilizarei o termo direito próprio da natureza (JONAS, 1995), na medida em que ela implica em uma reivindicação por um valor incondicional, em uma demanda pelo reconhecimento da natureza como tal e, portanto, em uma atitude de respeito pelos não humanos. Essa atitude é a base para aquele "contrato natural de simbiose e de reciprocidade", defendido por Serres (1994), por exemplo. Por outro lado, vou reservar o termo direito instrumental da natureza para me referir àquilo que resulta de algum cálculo em que a finalidade é sempre a própria humanidade e os meios são seres naturais.

É verdade que essas duas formas de reivindicação por direitos da natureza convivem dentro do ambiente contemporâneo. Também é verdade que do ponto de vista da luta ambientalista prática, eles não produzem resultados díspares. Pode mesmo ocorrer que o direito instrumentalproduza mais efeitos práticos do que o direito próprio, pelo menos nas condições políticas atuais e dentro de uma perspectiva temporal mais imediata.

Porém, há uma diferença básica entre eles que eu gostaria de destacar nesse artigo. O direito instrumental compartilha do conjunto de valores que caracterizam a civilização técnica do ocidente, nascida de certa reorganização do poder e do conhecimento a partir do Século XVI. Esses valores foram impulsionados pelo Iluminismo e sua fé no poder da racionalidade humana em produzir um mundo socialmente justo e individualmente feliz. Sabemos que essa confiança na racionalidade humana, típica da época de nascimento da 
civilização técnica, requereu uma postura específica com relação ao mundo natural. Essa postura é uma condição necessária para a vigência do direito instrumentalna medida em que nela o homem foi colocado como herdeiro de um suposto mandato divino sobre o mundo.

A postura a que me refiro - e que é a base cultural da técnica - promoveu a eliminação de qualquer traço de espiritualidade do mundo natural. Com efeito, a conversão da natureza em um instrumento pleno, em um receptáculo neutro para a projeção técnica de intenções humanas, requereu a retirada de qualquer vestígio de vida espiritual que pudesse servir como obstáculo a essas intervenções humanas.

Se a natureza fosse dotada de um significado próprio, certamente isso tornaria difícil ou mesmo impossível o processo de sua instrumentalização. Essa dificuldade consistiria na necessidade de se levar em conta esse significado em cada caso, já que ele envolveria um valor específico e próprio de cada ser natural. Com isso quero dizer que uma natureza espiritualizada e dotada de um significado intrínseco não pode ser reduzida a leis. A lei natural retira sua validade da suposição de que não há nada de significativo em cada ser não humano em particular e que os conjuntos desses elementos podem ser reunidos em categorias que desconsideram qualquer especificidade individual. Uma natureza dotada de significado próprio não pode ser reduzida a leis gerais que desconsideram a especificidade individual de cada ser que a constitui. Dessa forma, ela não pode ser objeto da técnica porque não pode ser reduzida a categorias. Permita-se ilustrar essa incompatibilidade entre a natureza espiritualizada e a técnica com um exemplo.

\section{O LIVRO SAGRADO}

Sabemos que a concepção medieval de natureza - portanto aquela que é historicamente anterior à concepção instrumental - envolvia compreendê-la como um livro divino (TAYLOR, 2010; BUARQUE DE HOLANDA, 2000). Nesse livro teriam sido escritas verdades metafóricas pelo próprio punho de Deus. O recurso ao uso de tais figuras metafóricas diz respeito à necessidade didática de não expor diretamente a frágil constituição intelectual dos seres humanos às verdades divinas superiores. A natureza seria, portanto, um recurso divino para ensinar lições morais ao homem sem, contudo, expô-lo àquilo que ele não poderia compreender diretamente, dadas as suas limitações.

Nesse caso, a relação apropriada do homem com a natureza, entendida como expressão cifrada da sabedoria divina, é a de um contemplador que interpreta e aprende algo que é maior que ele. Haveria nela sempre um significado oculto a ser decifrado, uma dimensão velada da realidade a ser descortinada sem a ilusão de, com isso, se obter a posse de um conhecimento exaustivo definitivo. Taylor (2010, p. 51) afirmou que na relação com essa natureza espiritualizada "o significado já existe fora de nós, é anterior ao contato; ele pode nos dominar, nós 
podemos cair em seu campo de força." A natureza é um livro sagrado em que estariam escritas verdades superiores e ao sábio caberia apenas tentar elucidá-las segundo seu ponto de vista pessoal, sem converter esse conhecimento em uma verdade universal. Nesse caso, não há alternativa senão representar o homem como inserido em uma totalidade transcendente dotada de um significado superior. Significado que só pode ser parcialmente apreendido por meio de um tatear sempre limitado e localizado.

A noção de que as laranjas eram eficazes para a cura do escorbuto, uma doença típica da época dos descobrimentos, devia-se à crença de que elas possuíam virtudes divinas especiais (BUARQUE DE HOLANDA, 2000). Ou seja, a eficácia estava ligada a certo poder intrínseco contido no mundo natural. A presença de uma cruz no interior de uma rodela de banana fatiada significava que a fruta era abençoada. A jabuticaba, ao contrário, era entendida como expressando a avareza humana, em função da maneira como suas raízes penetravam no solo, como se a agarrassem com excesso de determinação. Note como se transita, nesses exemplos, das características físicas para o significado moral dos seres naturais. Isso é possível porque o parâmetro de interpretação utilizado supõe que a natureza possui um significado superior, um sentido não natural que não pode ser inteiramente compreendido pelo homem. Ela propicia aquilo que Sousa (s.d.) caracterizou como uma perspectiva contemplativa - e que é obviamente distinta da postura técnica de conhecimento e de controle.

As fábulas envolvendo o comportamento animal expressam justamente esse entendimento da natureza como um grande livro que contém ensinamentos morais de maneira cifrada. Com a chegada do inverno, a laboriosidade das formigas é recompensada em detrimento do estilo alegre e irresponsável da cigarra, na conhecida fábula de La Fontaine (1966). A sagacidade do macaco também é premiada enquanto a violência e a tacanhice da onça são punidas, para citar um exemplo brasileiro de fábula (AZEVEDO, 2005).

Em todas as fábulas, a natureza transmite um significado moral. Ela contém uma lição a ser aprendida pelos homens e é fonte de um tipo de sabedoria a que não poderíamos chegar a não ser por meios metafóricos. Nelas a natureza é uma espécie de recurso retórico para ministrar lições éticas aos homens de acordo com suas capacidades limitadas de entendimento. Também nelas, a natureza mostra-se conectada com uma instância superior da existência, com uma dimensão oculta de valores especiais a que o homem não teria acesso direto. Seu significado sempre transcende aquilo que se supõe ser dado na própria situação natural e objetiva - no mundo dos fatos.

A subordinação do mundo natural à condição de instrumento, operada pela civilização técnica, requereu que essa suposta sabedoria divina inserida na natureza fosse eliminada, que os conteúdos morais implícitos nela fossem descartados como fantasia. Se a natureza fosse um livro divino, escrito em linguagem cifrada, sua subordinação técnica envolveria sempre um risco enorme. Isso porque, em caso de uma intervenção humana, se estaria sempre lidando com um significado oculto, com um possível valor divino e moral que poderia estar sendo 
infringido pelo homem. Ou seja, o uso da técnica envolveria sempre a possibilidade iminente de se cometer algum pecado contra o próprio Deus ou contra um sentido superior. Pois, na medida em que se manipulasse a natureza, parte daquele significado oculto superior poderia ser atingido ou danificado, em função da limitação epistemológica humana. O perigo nesse caso consistia em alterar uma ordem diretamente escrita pela mão de Deus e parcialmente inatingível para qualquer forma de sabedoria humana. Podemos observar, então, como uma natureza sagrada não pode ser manipulada pelo homem sem o risco de se infringirem leis divinas ou um regramento superior do mundo.

Considerada como um livro sagrado, a natureza possuiria um significado inesgotável diante da finitude de nossas habilidades cognitivas. Ou seja, trata-se aqui também de reconhecer as limitações de nossas capacidades racionais quando lidamos com uma natureza cujo significado transcende ao que é dado. Assim, uma natureza compreendida como dotada de um significado divino é sempre também a afirmação de nossa incapacidade de conhecê-la integralmente, de nossa pequenez epistemológica diante de seres naturais espiritualizados e, portanto, sempre transcendentes. Ela envolveria reconhecer que, afinal, só nos restaria a possibilidade de alguns ensaios interpretativos temporários, mas não de um conhecimento exaustivo do mundo natural. Isso é exatamente o contrário do que preconizava aquela fé iluminista nos enormes poderes da racionalidade - típica da época do nascimento da civilização técnica - a que me referi acima.

A necessidade de expurgar todo significado moral e todo valor próprio do mundo natural é derivado da necessidade de se destravar a potência da razão humana e, consequentemente, liberar o poder de domínio sobre o mundo natural. A manutenção daquela espécie de aura da natureza, aquele significado divino difuso e envolvente, impedia que ambos os poderes humanos pudessem ser exercidos sem freios: o poder de conhecê-la exaustivamente e o poder de controlá-la integralmente. A liberação dessas duas capacidades humanas constitui um mesmo processo, porque é o conhecimento exaustivo que permite o controle total, é o conhecimento que possibilita a expansão do poder de controle.

Os obstáculos presentes no conhecimento e controle dos seres não humanos foram removidos pela eliminação dos traços de vida espiritual da natureza, pelo expurgo de seus significados transcendentes, pela redução da dimensão ontológica dos não humanos a uma condição de pobreza. Isso permitiu o uso potencialmente ilimitado da razão e da técnica, do conhecimento e do poder na mesma proporção em que permitiu que os seres naturais individuais passassem a ser considerados membros indistinguíveis de um conjunto ou categoria.

Ressalto aqui essa importante conexão, que em geral não se encontra bem explicitada nas posições críticas com relação à técnica. A liberação das potências humanas de conhecimento e de controle da natureza envolvem um gesto inaugural de empobrecimento da dimensão ontológica dessa última. Somente por meio desse 
gesto inaugural é que a natureza torna-se um efetivo objeto de conhecimento, algo disponível em sua própria dimensão, sem traços de transcendência. A potencialização daquelas capacidades humanas se faz, portanto, de maneira simultânea à dilapidação da riqueza ontológica dos seres não humanos. Um dos processos alimenta o outro, como dois lados de uma mesma balança: à medida que um dos extremos tem seu peso ampliado o outro se torna consequentemente destituído de seu significado próprio.

Aquela consideração da natureza como redutível a um conjunto de leis, a que me referi antes, só se tornou possível porque o significado específico de cada ser natural foi reduzido a um mero exemplo ou ilustração da universalidade. Enquanto cada um deles era dotado de uma vida espiritual própria, não era possível considerálos como casos que especificavam uma lei. Somente com a eliminação do valor próprio de cada ser, eles passaram a poder ser incluídos em categorias gerais. Há, nesse processo, um verdadeiro esforço do pensamento científico para ignorar aquilo que constituía a individualidade de cada ser natural em benefício das leis e do tratamento impessoal (WELLS, 1995).

\section{O MONOTEÍSMO}

A lição valiosa que essa situação histórica nos ensina é que uma integração harmônica entre o valor instrumental da natureza com aquele sentimento que reivindica um valor próprio para ela é impossível em longo prazo. Com isso quero dizer que essas duas posturas, embora possam atualmente e em condições particulares produzir um aparente efeito sinérgico, são na verdade incompatíveis. Esse efeito sinérgico seria aquele que indicaria uma tendência geral, perceptível igualmente em ambos os casos, de valorização da natureza.

Com efeito, observe que o avanço prático do sentimento que requisita um valor próprio para a natureza não poderá ser conciliado com os demais valores da civilização técnica. Isso porque foram os requisitos fundadores da civilização técnica que demandaram a eliminação histórica da aura natural e favoreceram a instrumentalização. Essa última só se tornou possível em função do expurgo simultâneo de todos os significados próprios do mundo natural.

Afinal, para uma efetiva conversão da natureza em meio, foi necessário que ela deixasse de expressar verdades superiores, que ela perdesse a ligação com valores desconhecidos e se convertesse em uma coisa. Isso permitiu que ela pudesse funcionar como um receptáculo neutro para significados humanos projetados sobre ela. Para ser devidamente instrumentalizada, a natureza teve que passar a não possuir nenhum significado autônomo, nenhuma dimensão de valor própria, nenhuma moralidade interna. Sua objetividade foi construída sobre a base da impessoalidade e da amoralidade. Com isso, eliminou-se toda possibilidade de fabular sobre o mundo natural. Seus valores e significados passaram, então, a ser somente aqueles que ela incorpora enquanto um meio na relação 
instrumental, típica do domínio técnico.

Da perspectiva da civilização técnica se reconhecem a existência de leis naturais, de regras que regulam universalmente o curso de todos os eventos do mundo. Vimos que elas resultaram do processo de retirada do significado específico de cada ser não humano, da eliminação de seus componentes morais. E é justamente pelo conhecimento prévio dessas leis que uma intervenção técnica se torna possível. A inoculação de uma finalidade humana no reino natural só pode se mostrar eficaz se nela se observa a situação prévia existente, se nela se leva em conta o sistema geral das leis da natureza. Afinal, uma intervenção técnica precisa se mostrar eficaz, isto é, pertinente ao contexto natural em que ela é executada.

O que foi expurgado, na transição da natureza como um livro sagrado para a natureza entendida como instrumento e coisa, foi o significado superior e a possibilidade de que novas interpretações possam ser feitas a partir do mesmo conjunto de fenômenos. A abertura para uma dimensão superior de significados potenciais foi encerrada e a natureza tornou-se um sistema fechado em si mesmo. Esse significado potencial que antes se mostrava um tema inesgotável para as interpretações humanas recolheu-se para uma condição objetiva dada. Apenas um sistema fechado pode ser objeto de uma única interpretação verdadeira. Toda espiritualidade teve que ser removida para uma dimensão não natural, para uma região de difícil acesso que, ao mesmo tempo, tornava a natureza inteiramente transparente, neutra e disponível para a intervenção. $\mathrm{O}$ espírito então se recolheu para a distância interior da subjetividade humana ou para a distância de um passado remoto em que Deus teria criado o mundo natural. Em ambos os casos, a espiritualidade foi restringida a um domínio separado e distante e a natureza tornou-se próxima e disponível para a investigação e o domínio.

Nesse ponto, necessito introduzir um novo elemento que já está presente nessa exposição, porém de maneira implícita: as crenças monoteístas. O monoteísmo desempenhou um papel importante nesse recolhimento da espiritualidade para o reino distante de um Deus criador. Não estou afirmando que o monoteísmo é uma tática deliberadamente forjada para promover esse afastamento do valor da natureza requerido pela civilização técnica. Quero dizer que a promoção da instrumentalização da natureza beneficiou-se de crenças monoteístas já presentes e disponíveis na cultura ocidental.

Na verdade, essa promoção pôde utilizar-se do princípio cristão de um Deus único e criador do mundo. E, especialmente, daquele Deus criador que não interfere na história e nem realiza milagres, o Deus do cristianismo reformado. Thomas (1991) descreveu o lento processo de recuo das crenças mágicas de uma natureza espiritualizada em face do avanço dos elementos monoteístas na Inglaterra durante a implementação gradual da Reforma.

Também é conhecida a tese da estreita conexão entre os valores básicos do cristianismo reformado e da civilização técnica e capitalista (HEGEL, 1987; HOYKAAS, 1988; WEBER, 2000). Por isso, não me deterei nesse 
aspecto aqui. Apenas saliento o fato de que o expurgo de um significado superior do mundo natural, aquele que envolve um trabalho constante de interpretação de um sentido oculto e não totalmente revelável, envolveu a conjugação de forças culturais ligadas ao monoteísmo e, especialmente, ao cristianismo reformado.

Com isso, podemos notar que aquele sentimento que solicita um valor próprio para a natureza não só é incompatível com todas as modalidades de raciocínio instrumental, como também não pode ser conciliado com a maneira como o cristianismo lida com a natureza. Afinal, essa religião supõe que sejamos, nós os seres humanos, os herdeiros de um mandato divino sobre toda a terra, que somos o suprassumo da criação divina, aqueles em que se expressa uma semelhança especial com o criador. E é dessa perfeição, superioridade e beleza que derivamos nosso direito inquestionável sobre o restante do mundo. E se somos nós que temos o direito autêntico, então ou a natureza não o tem sob nenhuma hipótese ou só o tem por meio de uma concessão de nossa parte. Em ambos os casos, ela não possui um direito próprio.

Esse conjunto cristão de valores supõe que somos o último e mais perfeito elemento da criação, aquele que por se encontrar nessas condições privilegiadas, pode exercer domínio sobre todos os demais. A desvalorização da dimensão natural da existência encontra-se explícita nos valores cristãos. Agostinho (1996, p.147) afirma, por exemplo, que "Fique bem assente, antes de mais, que a virtude, norma de vida recta, dá as suas ordens aos membros do corpo a partir da sua sede, a alma, e que o corpo se santifica sendo o instrumento de uma vontade santa." (sic). Ou seja, o elemento natural que nos constitui, nosso corpo, só se torna santo quando se deixa governar e é dominado por nossa vontade.

A vida natural precisa, portanto, ser crucificada para que ela renasça purificada no mundo espiritual. Ela necessita ser submetida à vontade superior justamente porque seu valor é inferior ou simplesmente não existe. A dimensão natural, externa ou presente em nossa constituição corporal, só se torna ética quando é submetida. Daqui deriva o sentido superior e a moralidade de toda relação de domínio com as dimensões não humanas da existência. O domínio técnico torna-se justificado porque, por meio dele, elevamos a natureza a um patamar superior e a espiritualizamos. Esse postulado cristão permite afirmar que a civilização técnica é responsável por uma espécie de cruzada moral contra uma totalmente natureza bruta.

Observe, porém, que essa cruzada só obtém seu sentido com base na eliminação inicial da espiritualidade da natureza. Como ela foi antes convertida em algo sem significado próprio, tornou-se uma massa bruta destituída de moralidade que pode e deve ser submetida pela vontade humana. O resgate da brutalidade da natureza foi devidamente precedido do seu rebaixamento a essa condição totalmente destituída de vida espiritual. Assim, a submissão técnica dos seres naturais ao homem é uma autêntica elevação, uma obra civilizatória e humanizadora, a partir daquele estado de brutalidade a que eles se viram reduzidos antes.

A solução cristã de domínio justificado de uma natureza selvagem só faz sentido porque se criou antes o 
problema da brutalidade de uma dimensão natural destituída de espírito. Essa solução somente faz sentido dentro do quadro geral de carência espiritual a que a natureza se viu reduzida nos quadros tradicionais do próprio monoteísmo. Agostinho (1996) também é bastante explícito a respeito dessa armadilha de queda e restauração da natureza. Ele gasta grande parte de sua obra principal, $A$ Cidade de Deus, tentando eliminar as crenças politeístas romanas que atribuíam a cada dimensão da particular existência uma divindade própria. Ou seja, o gesto inaugural de justificação da salvação cristã envolve o rebaixamento da natureza a uma situação de miséria espiritual. Só há salvação para aqueles que se encontram originalmente em um estado de miséria espiritual. Portanto, esse estado de ausência de humanidade e de espiritualidade necessita ser afirmado como sendo a própria condição ontológica dos não humanos.

Há aqui, algo que não pode passar despercebido sob pena de se cometerem injustiças. O cristianismo, por mais de uma vez, de mostrou um defensor de valores igualitários. Esses valores levaram à expansão do reconhecimento de direitos para seres historicamente destituídos deles. No Brasil, pode-se citar a luta do Padre Antonio Vieira contra a escravidão dos indígenas ou mesmo o estado de guerra civil a que chegou a oposição entre os jesuítas e os produtores coloniais no Maranhão - ávidos pela subjugação incondicional do gentio. Tensão que, como se sabe, terminou com a expulsão dos jesuitas do Brasil pelo Marquês de Pombal (OLIVEIRA LIMA, 2000).

Note, entretanto, que a defesa explícita da posse de um valor específico por parte dos indígenas brasileiros - que se supunham brutos e não humanos - estende o direito somente para as dimensões da própria espécie humana. Claro que isso significou algo em termos de melhoria das condições de respeito à vida dos indígenas, principalmente quando considerarmos o contraponto de que os espanhóis nos primeiros tempos da colonização da América alimentaram seus cães com a carne deles (FAORO, 1973).

A promoção de certo igualitarismo interno, por assim dizer, não significa que o cristianismo esteja em condições de propiciar os requisitos culturais necessárias à validade daquele sentimento de um direito próprio da natureza a que tenho me referido aqui. Pelo contrário, como vimos acima, o conjunto de valores cristãos implica na legalidade divina do poder humano sobre o mundo natural e na necessidade de domínio da vontade sobre as potências não humanas - no homem ou fora dele.

Isso nos permite ter maior clareza sobre avanços e limitações típicas dessa religião no que diz respeito à ampliação de direitos e, consequentemente, formular um juízo mais ajustado sobre seu papel histórico com relação à natureza. Ela certamente beneficiou a ampliação dos valores democráticos por meio da promoção do reconhecimento de que todos os seres humanos são iguais. Porém, ela não parece apta a catalisar aquele sentimento de inclusão do mundo natural no sistema geral de direitos próprios.

$\mathrm{Na}$ verdade trata-se de uma limitação mais geral derivada dos princípios em que essa religião se estriba. 
Nenhuma forma de monoteísmo parece habilitada a desempenhar esse último papel. Justamente porque essa modalidade de religião tem como característica básica a retirada de todo significado específico do mundo natural. Significado natural que precisa ser absorvido pelo poder de um criador único, de maneira a dotar o monoteísmo de sua característica definidora: a existência de um único e onipotente Deus.

Isso significa que é da essência de todo monoteísmo a absorção e a concentração do valor autônomo da natureza em um espírito não natural e, portanto, a eliminação de um direito próprio da natureza, como o entendemos aqui. Ele necessita fagocitar esse valor do mundo natural porque o conteúdo de uma divindade única e exclusiva implica na concentração do poder em uma individualidade superior. Afinal, se essa religião fosse autenticamente democrática e distribuísse o valor espiritual entre várias modalidades de seres, ela não seria monoteísta. A dispersão da espiritualidade em diferentes instâncias naturais é o inimigo principal de todas as crenças monoteístas. Por isso Agostinho ocupou-se tão intensamente com o combate ao politeísmo romano no seu esforço para legitimar a religião cristã.

\section{CONCLUSÃO}

Temos, então, a seguinte situação no mundo contemporâneo: um sentimento crescente que demanda o reconhecimento de um valor próprio da natureza. Sabemos agora que nenhuma forma de monoteísmo pode facilitar sua implementação prática em longo prazo, porque essa modalidade de religião exerce uma força centrípeta sobre a cultura, cristalizando um núcleo exclusivo de poder e de sabedoria. É a coagulação desse núcleo dotado de imenso poder e de todo o conhecimento que retira do mundo natural seu direito próprio. Isso acontece porque esse último compromete a defesa de um deus onipotente e criador.

Chamo a atenção para uma segunda conclusão que não pode ficar implícita aqui. Vimos que a base da civilização técnica não promove o reconhecimento dos direitos próprios da natureza. Ao contrário, ela tende a reconhecer o seu valor instrumental: o valor dos não humanos enquanto meios para a realização de finalidades humanas. Então, o empenho consequente pela realização desse direito próprio da natureza constitui-se também como uma luta contra a hegemonia cultural da ciência ocidental.

Isso não quer dizer que os cientistas não possam lutar pela obtenção de um direito próprio por parte da natureza. Isso quer dizer que a cultura cientifica é incompatível com a obtenção do direito próprio da natureza, porque sua base é instrumental. Ou seja, os cientistas que lutam pelo direito próprio da natureza, lutam contra a própria cultura científica, mesmo a despeito de seu desejo bem intencionado de fazê-lo.

Além disso, como vimos acima, a expansão prática do sentimento que requer o reconhecimento de um valor próprio da natureza não poderá ser promissora dentro de um contexto cultural mais amplo em que 
dominam valores monoteístas. As religiões monoteístas são centrípetas e a reivindicação do direito próprio da natureza exerce uma direção centrífuga sobre a espiritualidade. Nesse último caso, o sentido do movimento envolve fragmentar e democratizar o acesso a um significado de que, hoje, os seres não humanos ainda estão destituídos.

No conjunto, a luta pela obtenção de direitos próprios para a natureza envolve tanto o enfraquecimento da cultura científica ocidental quanto das religiões monoteístas. Essa parece ser a dupla e incontornável tarefa de um sentimento que pretende obter, do ponto de vista prático, a posse de direitos próprios por parte dos seres não humanos. Se isso ocorrer, o avanço prático desse sentimento, a conquista de mentes e corações, implicará também o enfraquecimento das crenças monoteístas e da cultura científica da civilização técnica.

Isso não significa que isso ocorrerá necessariamente. Afinal, o autor não possui dons mediúnicos. Tratase aqui de verificar que o avanço do sentimento que reivindica um direito próprio para a natureza terá que conquistar terreno contra o monoteísmo e contra a cultura científica atual. Pode ocorrer que esse sentimento seja subjulgado por essas forças civilizatórias e que ele perca seu ímpeto. Pode ser que nesse processo de subjugação, se preserve apenas sua tendência geral, porém dentro de um quadro instrumental: a de propiciar o reconhecimento de um direito para a natureza. Nesse caso, aquele sentimento seria domesticado pelos valores antagônicos na medida em que terminaria propiciando o avanço de um direito instrumental para os seres não humanos. Seja como for, os termos que tensionam o ambiente contemporâneo com relação à questão dos direitos da natureza parecem ser os que foram descritos nesse artigo. $O$ desenlace cultural futuro dessas tensões escapa inteiramente às capacidades desse autor.

\section{THE RIGHTS OF NATURE}

\section{Abstract}

The article begins with the realization that there is a growing sense in contemporary culture, which demands respect for non humans. In turn, this feeling calls for recognition of the rights of nature. From this observation, are distinguished two basic positions that try to make this demand effective: the instrumental right and the own right. The first maintains an instrumental reasoning that is typical of technique. The second cannot be reconciled with that kind of reasoning. To gain clarity quickly it compares the medieval notion of nature to that which provided the basis for modern science and historically allied it with monotheistic beliefs, especially Christian beliefs. It concludes with the realization that getting an effective cultural validity to the proper law of nature, if it occurs, will 
result in two battlefronts not inconsiderable. One against monotheistic beliefs and the other against the base of Western scientific culture.

Keywords: Nature; Right; Science; Technique; Monotheism

\section{REFERENCIAS}

AGOSTINHO. A cidade de Deus. Lisboa: Calouste Gulbenkian, 1996.

AZEVEDO, R. Contos de bichos do mato. São Paulo: Ática, 2005.

BERTALANFFY, L. Teoría General de los Sistemas. Editorial Fondo de Cultura Económica. México. 1976.

BUARQUE DE HOLANDA, S. Visão do paraíso: os motivos edênicos no descobrimento e colonização do Brasil. São Paulo: Brasiliense/Publifolha, 2000.

FAORO, R. (Org.) O debate político no processo da independência. Rio de Janeiro: Conselho Federal de Cultura, 1973.

HEGEL, G. W. F. Lecciones sobre filosofía de la religión 1, 2 e 3. Madrid: Alianza Editorial, 1987.3v.

HOOYKAAS, R. A religião e o desenvolvimento da ciência moderna. Brasília: Editora da UnB, 1988.

JONAS, H. El principio de La responsabilidad: ensayo de una ética para la civilización tecnológica. Barcelona: Herder, 1995.

LA FONTAINE. Fables. Paris: Garnier/Flammarion, 1966.

MORIN E. Introdução ao pensamento complexo. Porto Alegre: Sulina; 2006. 
OLIVEIRA LIMA. Formação histórica da nacionalidade brasileira. Rio de Janeiro/São Paulo: Topbooks/Publifolha, 2000.

SERRES, M. O contrato natural. Lisboa: Instituto Piaget, 1994.

SOUSA, G. S. de. Tratado descritivo do Brasil em 1587. s. l.: s. e., s.d.

TAYLOR, Ch. Uma era secular. São Leopoldo: Editora UNISINOS, 2010.

THOMAS, K. A religião e o declínio da magia. São Paulo: Companhia das Letras, 1991.

WEBER, M. A ética protestante e o espírito do capitalismo. São Paulo: Editora Pioneira, 2000.

WELLS, H. G. A redescoberta do único. Estudos Avançados, V.9, N. 25, 1995, p. 263-270.

Trabalho enviado em 23 de fevereiro de 2018

Aceito em 04 de abril de 2018 